\title{
Incremental Deployment Aspects of beyond 4G and 5G Mobile HetNets
}

\author{
Vladimir Nikolikj ${ }^{1}$ and Toni Janevski ${ }^{2}$ \\ ${ }^{1,2}$ Ss. Cyril and Methodius University, Faculty of Electrical Engineering and \\ Information Technologies, Karpos 2 bb, 1000 Skopje, Macedonia \\ ${ }^{1}$ vladimir.nikolikj@onevip.mk; ${ }^{2}$ tonij@feit.ukim.edu.mk
}

\begin{abstract}
In this paper, we perform the analysis of cost effective capacity expansion strategies with incremental deployment aspects of the forthcoming mobile heterogeneous networks from beyond $4^{\text {th }}$ and $5^{\text {th }}$ generation. We consider different over time (up to year 2025) increasing traffic volumes in order to determine the most cost-effective capacity expansion that would minimize aggregate incremental cost. In this aspect, we determine that deployments with base stations having smaller ranges offer a lower investment risk on long term, because incremental capacity can be satisfied in smaller stages. This is especially due to the fact that the cost structure of smaller base stations is dominated by operational expenditures as compared to, in the other extreme, a new macro base station site. From this perspective, our techno-economic analysis proposes a model that would be useful to analyze the economic viability of different type of traffic growth volumes and for various forthcoming heterogeneous network configurations.
\end{abstract}

Keywords: 4G, LTE-Advanced, 5G, Millimeter wave, IEEE 802.11n, IEEE 802.11ac, Incremental Cost, Total Cost of Ownership (TCO), Net Present Value (NPV), Average Revenue per User (ARPU), Cost-capacity modeling

\section{Introduction}

Future mobile networks from the fifth generation $(5 \mathrm{G})$ will be heterogeneous in its nature (HetNet) [1]. This means that Radio Access Networks (RAN) will be based on one or few Radio Access Technologies (RATs), with hierarchically ranged macro (MaBS), micro (MiBS), pico (PBS) and femto (FBS) base stations (BS) sites, complemented with particular wireless local area network (WLAN or Wi-Fi) access points (AP). Nevertheless, even the HetNets from the near future (to utilize e.g., RAT like 4G LTE-Advanced) are facing important issue, as they are designed to operate within the restricted microwave spectrum. Thus, according to [2], the "millimeter wave $(\mathrm{mmW})$ interface" is considered as one of the five potentially disruptive technologies and approaches that could lead to both architectural and component design to serve as basis for the 5G cellular network. Authors in [3-8], have presented substantial practices for the new high capacity $\mathrm{mmW}$ cellular systems, providing extreme capacity through the huge amount of the available spectrum in the $\mathrm{mmW}$ bands $(28 \mathrm{GHz}-300 \mathrm{GHz})$.

Consequently, such potentials for further improvements within the next few years and even current astonishing performances of the $\mathrm{mmW}$ based $5 \mathrm{G}$ systems, were our exact motivation, to assess their feasibility from techno-economic perspective they to become the main components of the future 5G HetNets and to assess their ability together with microwave RATs and advanced Wi-Fi to contribute to bridge the downgrade trend of the profitability in the telecommunications industry. Related to this, also we consider the of Wi-Fi deployment based on the IEEE 802.11ac standard 
(known as "Gigabit Wi-Fi") ensuring high capacity gains apart of the sufficient coverage.

Hence, in this article using a case study of incremental cost based network deployment strategies, we present the comparative cost-capacity modeling of beyond $4 \mathrm{G}$ and $5 \mathrm{G}$ based HetNets. Our goal is to assess various reliable capacity expansion strategies for a mobile network operator (MNO) challenged to satisfy also various traffic growth scenarios based on the mobile data demand, within the forthcoming period 2017-2025. Thus, from the deployment layout mainly based on the BSs with higher ranges, used as reference, we compare in the time period of 9 years, different paths to upgrade or introduce new additional BSs/APs sites in the "hot spot" areas. The outcomes present sufficient findings needed one to be able to determine which type of capacity expansion strategy would diminish aggregated incremental cost or the total cost of ownership (TCO) for particular expected traffic growth pattern. Also, we put special focus on the time component in the research related to the moment when particular investment is done, since a solution that minimizes incremental costs in the short run may be cost inefficient in the long run if traffic demand bursts significantly, and opposite.

This paper consists of 8 sections. Section 2 gives a survey of the most relevant related research. Section 3 covers a network dimensioning and traffic modeling approach used. Next, we describe the possible capacity expansion strategies in front of the MNO. Section 5 describes the specific coverage and capacity analysis. Further, we elaborate the cost modeling with special accent on the incremental deployment aspects. Prior the conclusion section, the findings related to the incremental cost analysis are delivered.

\section{Related Works}

We base our techno-economic analysis to the references [9-24] covering the various aspects of cost-efficient capacity expansion strategies of HetNets using multi-RAT or multi-BS/AP solutions. We particularly base our incremental cost analysis with non-steady state traffic conditions based on $[9,17,23]$. More precisely, these publications cover the differences between deployments that minimize costs in different time perspectives. Thus, [9] considers for the macro layer the HSPA and in last stage of the time period under analysis only the LTE, where the hotspots are covered by Wi-Fi APs equipped with IEEE 802.11a and IEEE 802.11n equipment. Analysis of cost aspects over time using the LTE RAT in the macro layer complemented with FBS sites and IEEE802.11g and IEEE802.11n for the hot spot layer are covered in [17]. The both, [9] and [17] only consider a single carrier frequency in the macro cellular layer by what the incremental cost estimates presented there could be slightly overestimated. Furthermore, authors in [9] consider two traffic growth scenarios (a conservative and high growth) across the years and [17] and [23] single traffic growth scenarios, by what obtained results for the aggregated incremental cost are more limited from the differentiation point of view. Furthermore, most of the results presented in these papers are based on the use of microwave frequency bands higher than $800 \mathrm{MHz}$ [20] and lower than 2.6 $\mathrm{GHz}$ bands and the use of system bandwidth ranging from $5 \mathrm{MHz}, 10 \mathrm{MHz}$ [23], 15 $\mathrm{MHz}$, [9], and up to maximum $20 \mathrm{MHz},[13,14,17]$. Here, we focus on various types of RATs that enable very high spectral efficiency over carriers having bands ranging from $500 \mathrm{MHz}$ to more than $2.0 \mathrm{GHz}$ in mmW spectrum frequency bands, and those below $800 \mathrm{MHz}$ and up to $2.6 \mathrm{GHz}$ in the microwave segment, with the use of carrier aggregation functionality.

Consequently, in this article we originally propose incremental cost analysis, through determination of aggregate incremental (non-discounted) expenditures per 
year or the TCO over the longer period and based on multi carrier deployments with recent and future advanced RATs like $5 \mathrm{G} \mathrm{mmW}$, LTE-Advanced, Wi-Fi IEEE 802.11 $\mathrm{n}$ and IEEE 802.11ac. We assume HetNets consisted of MaBS sites which are complemented with MiBS sites and Wi-Fi AP sites. For each of the considered BS/AP types we use as a baseline "up to date" cost drivers for the capital (CAPEX) and the operational (OPEX) expediters. Also, compared to previous related researches, we consider three different traffic growth scenarios (two linear (low and high) and one following the so called sigmoid growth function), by what we increase the reliability of the obtained results compared to previous related researches. With this regard, we consider various shares of heavy users, various shares of three types of user terminals, various amount of data usage per hour and with different values of user activity across the day. Further, according to our best knowledge, we assess for the first time the potential benefits of using spectrum in the $\mathrm{mmW}$ bands in prospect of obtaining the positive NPV for each year in the considered period, in a way that we determine the average revenue per user (ARPU) increments on monthly level over the time.

As a final point, the considered techno-economic framework in this article is a subsequent stage from our previously published related work on the comparative cost-capacity analysis of the future wireless HetNets e [25-30]. The difference in the approach in this article compared to our previous researches is that here, we consider capacity expansion strategies as a function of not constant traffic load. Even though that such approach in our previous research provides important understandings on the cost-capacity relationship based on the various network deployments, the time variable was not strictly addressed. Consequently, here we focus on the strategies to match the deployment of the radio access network (RAN) over the time or with consideration of the growing traffic volumes.

\section{Wireless HetNet Dimensioning and Traffic Modeling}

For the network dimensioning, we assume a densely populated urban area. As reference for the population density of $\theta$ (users $/ \mathrm{km}^{2}$ ), we consider the capital city of the France, Paris, having the highest population density in Europe with around 22,000 citizens per $\mathrm{km}^{2}$ [31]. Further, we consider a mobile broadband penetration of $75 \%$ and we focus our analysis at incumbent MNO with $60 \%$ market share. Consequently, our analysis relies on 10,000 users $/ \mathrm{km}^{2}$ assumed to be the constant user base of the MNO during the period 2017-2025.

As outlined in [9], to predict traffic demand for wireless access services is not easy goal to be achieved. In such case, it has to be considered both, the exogenous and endogenous factors. According to [32], most common exogenous factors that could be identified are: competition, availability of substitutes and network externalities. Furthermore, according to [33], also the population and income could be considered as exogenous factors, and all endogenous changes in volume are considered as movements along the demand curve. Thus, according to [34] besides consideration of mobile data traffic forecast being exogenous factor, also demand for data should be modelled in an endogenous way by consideration of the price for data demand and therefore on spectrum demand, taking into account the network costs and consumers' willingness to pay for data.

In this article, we consider that the traffic prediction is combination of both exogenous factors that impact the demand curve, and endogenous factors that determine the pricevolume correlation of the demand. Nevertheless, for the sake of manageability, we assume traffic growth to be mostly exogenous in its nature (regardless that we acknowledge that this is not fully the case). This approach is also considered in [9]. Accordingly, we analyze the following three traffic growth scenarios: 
1. "Mobile broadband - low demand scenario" with linear traffic growth (MBB LIN LOW),

2. "Mobile broadband - high demand scenario" with linear traffic growth (MBB LIN HIGH), and

3. "Broadband fix replacement" - traffic growth tends to increase according to a sigmoid shape function [32, 35] (BB REP SIGMO).

In the both scenarios of mobile broadband we consider regular traffic growth pattern where most of the traffic is handled via other access networks, like fixed. From other side, broadband replacement scenario is traffic scenario bringing excessive growth where a significant number of users mostly use data via the mobile access. Also, for the sake of simplicity, we put our focus only on downlink services only as currently being more bandwidth demanding. Having in mind that the traffic volumes per user tend to increase significantly due to higher data rates enabled and due to introduction of new services, for the traffic forecast phase in line with [23] [36], we consider the long term large scale traffic model that estimates the area traffic demand in an average European dense urban city for a given year. According to this model, the daily generated traffic $G(t)$ over a given area can be defined as a function of $\theta$ as follows:

$$
G(t)=\theta \cdot \Lambda(t) \sum_{k} g_{k} \cdot t_{k} \quad\left[\mathrm{Mbit} / \mathrm{s} / \mathrm{km}^{2}\right]
$$

where $\Lambda(t)$ represents a typical daily traffic variation in terms of percentage of number of active users for a given time $t$ and $g_{k}$ and $t_{k}$ represent the average data rate and the fraction of the subscribers using terminal type $k$, respectively.

In line with [36], we consider three different terminal types: laptop, tablet and smartphone. Further in the analysis, we consider the fraction of the subscribers using particular terminal type $k$. According to [37], smartphones, tablet, and laptops consisted $97.8 \%$ in 2014 and will consist $97.6 \%$ of the traffic generated via mobile access network in 2019 (the rest belongs to non-smartphones, machine-to-machine (M2M) modules, and wearable devices). Consequently, here we consider the fraction of the users using these three terminal types with reasonable assumption that particular users have more than one active terminal type in use. By this, our calculations show that the number of used device per $\mathrm{km}^{2}$ will surpass the number of users per $\mathrm{km}^{2}$ as of 2020 .

According to $[36,23]$ in year $2015,20 \%, 5 \%$ and $50 \%$ of the population are PC, tablet and smartphone (mobile) users, respectively. Based on [9], in year 2016 the smartphones share will be 30\% and the laptop shares will be between 15-30\%. For year 2014, [37] considers the smartphone share of 29\%. Consequently, we consider for the year 2015 20\%, 5\% and 30\% share for the laptop, tablet and smartphone respectively, and this year is the reference for the analyzed period 2017-2025. Further according to [37], we assume the Compound Annual Growth Rate (CAGR) in devices for the period 2017-2019 as $16.7 \%$, 32\%, and 5.3\% for smartphones, tablets, and laptop, respectively. For the period 2020-2025, we assume two times lower CAGR, as we expect the growth of the devices to slow down in the last period of the observation, what is especially valid for the growth trends following the sigmoid function.

Next, we study different assumptions for each of the three traffic growth scenarios. Namely, as in [23], we assume that users are divided into two groups (i.e., users with heavy and regular data demand) where the capacity requirement of a regular user is $12.5 \%$ of the one of a heavy user. Under the assumption that $h \%$ of the subscribers are categorized as heavy users, the average daily data rate for terminal $k$ can be defined as: 
$g_{k}=\left[h \cdot g_{k}^{\text {heauvy }}+(100-h) g_{k}^{\text {regular }}\right] / 100 \quad[$ Mbit/s $]$

Here $g_{k}^{\text {heavy }}[\mathrm{Mbit} / \mathrm{s}]$ and $g_{k}^{\text {regular }}[\mathrm{Mbit} / \mathrm{s}]$ represent the hourly average data rate of a heavy and an regular user, respectively, what can be calculated based on the estimated hourly average usage of a heavy and a regular user $G_{k}^{\text {heavy }}[\mathrm{MB} / \mathrm{hour}]$ and $G_{k}^{\text {regular }}[\mathrm{MB} / \mathrm{hour}]$, based on the following equation:

$$
g_{k}^{\text {heavy } / \text { regular }}=G_{k}^{\text {heavy } / \text { regular }} \cdot 1024 \cdot \frac{8}{3600} \quad[\text { Mbit/s] }
$$

In order to reflect the expected traffic growth of the three considered scenarios across the years within the analyzed period, we adjust different traffic growth pattern, different ratio of heavy users and fraction of the subscribers using particular terminal $s_{k}$ as elaborated above. For all three scenarios, we use as reference the assumed traffic volumes in 2015 according to [36]. In particular, for 2015, we consider that heavy laptop user consumes traffic load of $R_{\text {laptop }}=900 \mathrm{MB} / \mathrm{hour}$ and according to [23], we consider that on average a tablet and a smartphone user generates two and eight times less data traffic than laptop user, or $450 \mathrm{MB} /$ hour and 112.5 MB/hour, respectively.

Furthermore, according to [37], for the period 2014-2019 the growth in mobile data traffic has CAGR of $22.3 \%, 83.4 \%$, and $60.1 \%$ for the laptop, tablet and smartphone, respectively. This analysis perceives rather high offload onto the fixed network through Wi-Fi or femtocell which increases from $45 \%$ in 2014 to $54 \%$ by 2019. Also, as outlined into [37], without offload, mobile data traffic would have grown $84 \%$ rather than $69 \%$ in 2014 , and total mobile data traffic would grow at a CAGR of $62 \%$ between 2014 and 2019, instead of the projected CAGR of 57\%. We follow exactly this approach for the MBB LIN LOW scenario, where we consider these CAGR values to continue up to 2025. Regarding the percentage of the subscribers classified as heavy for this scenario, we consider that in 2017 there will be $25 \%$ of the users treated as heavy for all three types of devices, and after, this share will continue to increase linearly for 2 p.p. year on year.

\section{Table 1. Peak Area Traffic Demand [Gbps/Km2] for the BB REP SIGMO Scenario with Estimated Area Traffic Demand in a Dense Urban for the Period 2017-2025}

\begin{tabular}{|c|c|c|c|c|c|c|c|c|c|c|c|c|}
\hline \multirow[t]{2}{*}{ Year } & \multirow[b]{2}{*}{$\begin{array}{l}h \\
\%\end{array}$} & \multicolumn{3}{|c|}{ Laptop } & \multicolumn{3}{|c|}{ Tablet } & \multicolumn{3}{|c|}{ Smart phone } & \multirow[b]{2}{*}{$\Lambda$} & \multirow{2}{*}{$\begin{array}{c}G \\
G b p \\
s / k m \\
2\end{array}$} \\
\hline & & $t_{k}$ & $G_{k}^{\text {heavy }}$ & $g_{k}$ & $t_{k}$ & $G_{k}^{\text {heavy }}$ & $g_{k}$ & $t_{k}$ & $G_{k}^{\text {heavy }}$ & $g_{k}$ & & \\
\hline 2017 & 25 & 22.2 & 3600 & 2.7 & 8.7 & 1800 & 1.3 & 40.9 & 450 & 0.3 & 16 & 1.4 \\
\hline 2018 & 43 & 23.4 & 7200 & 7.9 & 11.5 & 3600 & 3.9 & 47.7 & 900 & 0.9 & 32 & 8.7 \\
\hline 2019 & 51 & 24.6 & 14440 & 18.2 & 15.2 & 7200 & 9.1 & 55.6 & 1800 & 2.3 & 64 & 45 \\
\hline 2020 & 59 & 25.2 & 28800 & 40.8 & 17.6 & 14400 & 20.4 & 60.3 & 3600 & 5.1 & 74 & 122 \\
\hline 2021 & 65 & 25.9 & 57600 & 88.2 & 20.4 & 17280 & 26.4 & 65.3 & 4320 & 6.6 & 85 & 270 \\
\hline 2022 & 68 & 26.6 & 69120 & 110.2 & 23.7 & 20736 & 33.1 & 70.8 & 5184 & 8.3 & 93 & 391 \\
\hline 2023 & 71 & 27.3 & 76032 & 126.2 & 27.5 & 22810 & 37.8 & 76.7 & 5702 & 9.4 & 95 & 483 \\
\hline 2024 & 75 & 28.0 & 79834 & 138.1 & 31.9 & 23950 & 41.4 & 83.1 & 5988 & 10.3 & 97 & 572 \\
\hline 2025 & 78 & 28.8 & 79834 & 143.9 & 37.0 & 23950 & 43.1 & 90.0 & 5988 & 10.8 & 99 & 647 \\
\hline
\end{tabular}


As summary, using (1) in combination with the forecasted values of $h$, the fraction of the subscribers using the three terminal types (i.e., $t_{p c}, t_{\text {tablet }}, t_{\text {s.phone }}$ ), and the average data rate requirements for a heavy user $r_{k}^{\text {heaavy }}$, we calculate the peak area traffic demand at the busy hour as $G\left[\mathrm{Gbps} / \mathrm{km}^{2}\right]=\max _{t}(G(t))$. The resulting average area throughput on downlink for the three traffic growth scenarios is presented in Figure 1. Table 1 summarizes all of the estimated values used as input for the BB REP SIGMO scenario. Regarding the MBB LIN HIGH scenario, we again consider gradual increase of the traffic per each user type as in the MBB LIN LOW scenario, with that difference that now we assume the share of the heavy users to be $40 \%$ until 2019 , and then the share of heavy and regular users to be equal for each type of device. For the third or BB REP SIGMO scenario, we assume that the traffic growth is more modestly but gradually increased to $20 \%$ until 2022 and then decreased, with such note that in this case we consider much higher gradual growth of the share of the heavy users which ends with $78 \%$ in the last year.

Finally, we consider various values of the indicator $\Lambda(t)$ representing the number of subscribers which are active during the busy/peak hour. Thus, for the MBB LIN LOW scenario, according to [36] we consider the maximal value of $16 \%$ active users during the busy hour in 2015, which figure is further gradually increased for 2 p.p. until 2025 yielding $32 \%$ or $\Lambda_{M A X}=32 \%$ in the last year. The same reference of $\Lambda(t)$ in 2015 is used for the BB REP SIGMO scenario, but now we consider much higher growth of the user activity that is gradually increased for $100 \%$ (peak growth 2019) and then decreased, by what the $\Lambda_{M A X}$ in the last year is assumed to be almost maximal or $99 \%$. For the MBB LIN HIGH scenario, we consider the activity of $40 \%$ until 2019, and then activity is kept stable to 50\% until the last year.

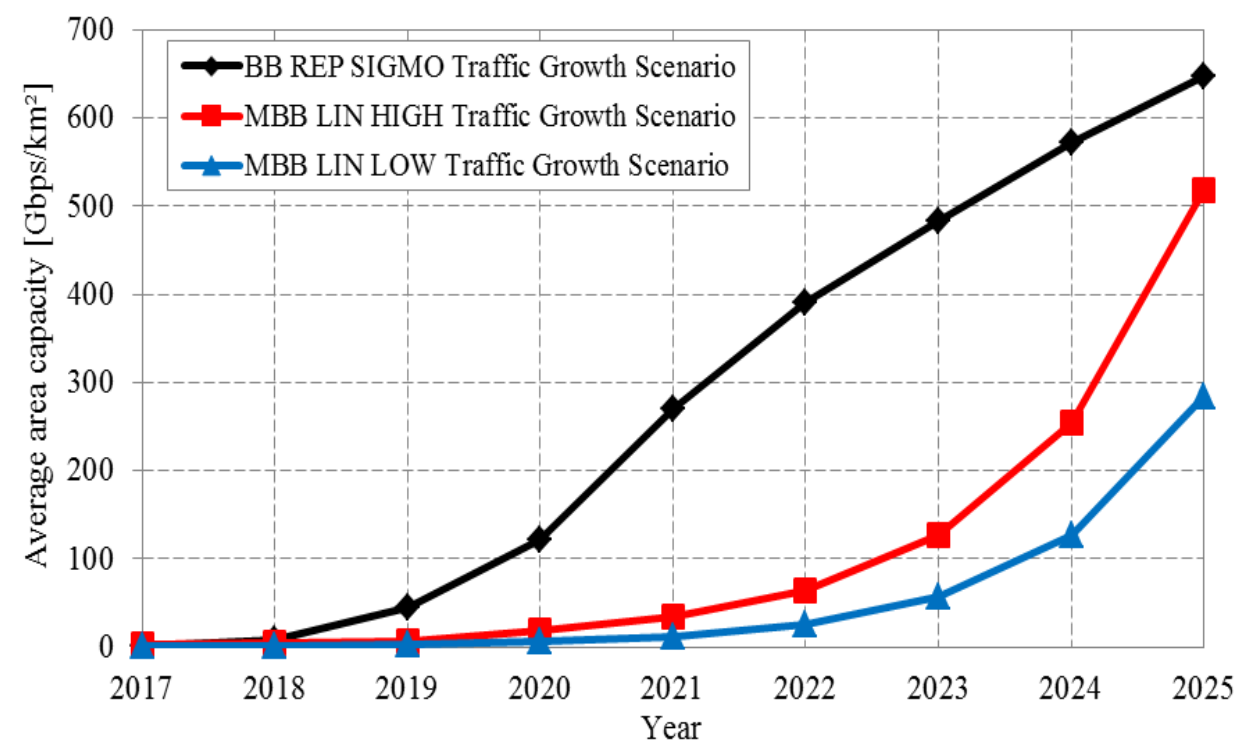

Figure 1. Average Area Capacity for the Three Traffic Growth Scenarios

\section{HetNet Expansion Strategies}

Author names and affiliations are to be centered beneath the title and printed in Times New Roman 12-point, non-boldface type. (See example below) Different expansion strategies can be identified by the MNOs when satisfying the three traffic growth scenarios analyzed in this article. According to [9], for the numerical evaluations, 
we consider two expansion paths based on future development of cellular networks and one path based on multi radio access technology approach, as follows:

1. "Multi-RAT" (M-RAT): LTE-A MaBS sites are complemented with different standards of IEEE enabled Wi-Fi APs. 5G mmW cellular upgrades are considered in the last three years of the period under consideration.

2. "Cellular development" (CEDE): LTE-A RAT as the macro cellular layer is complemented with dense MaBSs sites or MiBSs sites in hot spots in the short term (under the hotspot, we define the " $\Delta$ " or extra traffic between two moments of consideration in the time, e.g. year on year). In the mid-term, installation of additional carriers to the LTE-A MaBSs is considered. In the long term, 5G MiBS sites are brought.

Out of the first expansion path, we consider the scenario titled as "M-RAT", and out of the second, the scenarios CEDE-I and CEDE-II. Further, we consider that the starting layout is a regular macro cellular network enabled with LTE RAT with single carrier frequency. After, for the period 2017-2019, the network is upgraded according to the specifics of each expansion strategy, or: deployed BSs are enriched and new BSs are, if necessary, deployed in hot spots [9]. We consider that in the mid-term, the cellular development depend on an upgrade with an additional carriers due to the carrier aggregation functionality of the LTE-A. The $5 \mathrm{G} \mathrm{mmW}$ is assumed to replace the previous hot spot layer in cellular evolution paths and is introduced in the last time of the considered period.

Form other side, with the M-RAT expansion strategy, we consider that LTE-A is deployed at MaBS sites and Wi-Fi APs are used in the hot spots, or the cellular RAT is used alternatively in MaBS sites and Wi-Fi technology in APs. Also, in this case the $5 \mathrm{G} \mathrm{mmW}$ cellular upgrades are considered in the last years with continuous introduction of additional carriers (up to three to be aggregated). In line with [9], we also consider that all BSs are upgraded with the respective evolved standard during the same year. Table 2, summarizes the discussed expansion strategies for the MNOs up to the year 2025.

Table 2. Cellular-Development and Multi-Access Capacity Expansion Strategies

\begin{tabular}{|c|c|c|c|c|c|c|c|c|c|}
\hline $\begin{array}{l}\text { Expan. } \\
\text { Str. }\end{array}$ & 2017 & 2018 & 2019 & 2020 & 2021 & 2022 & 2023 & 2024 & 2025 \\
\hline $\begin{array}{l}\text { M- } \\
\text { RAT }\end{array}$ & \multicolumn{2}{|c|}{$\begin{array}{c}\text { LTE-A } \\
\text { MaBS (3c.) } \\
+ \\
\text { IEEE } \\
802.11 \mathrm{n} \\
\end{array}$} & \multicolumn{2}{|c|}{$\begin{array}{c}\text { LTE-A } \\
\text { MaBS (3c.) + } \\
\text { IEEE } 802.11 \mathrm{ac}\end{array}$} & $\begin{array}{l}+5 \mathrm{G} \\
\mathrm{MiBS} \\
(1 \mathrm{c} .) \text { at } \\
\text { MaBS } \\
\text { site }\end{array}$ & $\begin{array}{c}+5 \mathrm{G} \\
\text { MiBS } \\
\text { (upgrad } \\
\text { e 1c.) }\end{array}$ & $\begin{array}{l}5 \mathrm{G} \\
\mathrm{MiB} \\
\mathrm{S} \\
(2 \mathrm{c} . \\
\text { total })\end{array}$ & $\begin{array}{l}+5 \mathrm{G} \\
\text { MiBS } \\
\text { (upgra } \\
\text { de } \\
1 \mathrm{c} .)\end{array}$ & $\begin{array}{c}5 \mathrm{G} \\
\mathrm{MiB} \\
\mathrm{S} \\
(3 \mathrm{c} . \\
\text { total })\end{array}$ \\
\hline $\begin{array}{l}\text { CEDE- } \\
\text { I }\end{array}$ & \multicolumn{2}{|c|}{$\begin{array}{l}\text { Dense MaBS } \\
\text { LTE-A (3c.) }\end{array}$} & \multicolumn{2}{|c|}{$\begin{array}{l}\text { LTE-A MaBS } \\
\text { (upgrade with } \\
2 \mathrm{c} \text {.) }\end{array}$} & $\begin{array}{c}+5 \mathrm{G} \\
\mathrm{MiBS} \\
(1 \mathrm{c} .) \text { at } \\
\text { MaBS } \\
\text { site } \\
\end{array}$ & $\begin{array}{c}+5 \mathrm{G} \\
\mathrm{MiBS} \\
(1 \mathrm{c} .)\end{array}$ & $\begin{array}{c}5 \mathrm{G} \\
\mathrm{MiB} \\
\mathrm{S} \\
(2 \mathrm{c} . \\
\text { total }) \\
\end{array}$ & $\begin{array}{c}+5 \mathrm{G} \\
\mathrm{MiBS} \\
(1 \mathrm{c} .)\end{array}$ & $\begin{array}{c}5 \mathrm{G} \\
\mathrm{MiB} \\
\mathrm{S} \\
(3 \mathrm{c} . \\
\text { total }) \\
\end{array}$ \\
\hline $\begin{array}{l}\text { CEDE- } \\
\text { II }\end{array}$ & \multicolumn{2}{|c|}{$\begin{array}{c}\text { LTE-A } \\
\text { MaBS (3c.) } \\
+ \text { New LTE- } \\
\text { A MiBS } \\
\text { (1c.) }\end{array}$} & \multicolumn{2}{|c|}{$\begin{array}{l}\text { LTE-A MiBS } \\
\text { (upgrade with } \\
\text { 1c.) }\end{array}$} & $\begin{array}{c}+5 \mathrm{G} \\
\mathrm{MiBS} \\
(1 \mathrm{c} ., \\
\text { replace } \\
\text { LTE-A) }\end{array}$ & $\begin{array}{c}+5 \mathrm{G} \\
\mathrm{MiBS} \\
(1 \mathrm{c} .)\end{array}$ & $\begin{array}{l}5 \mathrm{G} \\
\mathrm{MiB} \\
\mathrm{S} \\
(2 \mathrm{c} . \\
\text { total })\end{array}$ & $\begin{array}{l}+5 \mathrm{G} \\
\mathrm{MiBS} \\
(1 \mathrm{c} .)\end{array}$ & $\begin{array}{c}5 \mathrm{G} \\
\mathrm{MiB} \\
\mathrm{S} \\
(3 \mathrm{c} . \\
\text { total })\end{array}$ \\
\hline
\end{tabular}

Note: abbreviation "c." stands for "carrier". 


\section{RAT Specific Parameters Assumptions}

The second and following pages should begin 1.0 inch $(2.54 \mathrm{~cm})$ from the top edge. On all pages, the bottom margin should be 1-3/16 inches $(2.86 \mathrm{~cm})$ from the bottom edge of the page for $8.5 \times 11$-inch paper; for A4 paper, approximately 1-5/8 inches $(4.13 \mathrm{~cm})$ from the bottom edge of the page. A BS of class $i$ is characterized by a maximum average throughput, related to capacity (bit/s), and cell range $r(\mathrm{~km})$ related to coverage $\left(\mathrm{km}^{2}\right)$. For all BS/AP classes in this article, we dimension the site coverage as circle area $\left(A=\pi r^{2}\right)$.

As outlined in [13], based on the system parameters from [38] on antenna heights, wall propagation losses $(20 \mathrm{~dB})$ and on antenna diversity, the range of the urban cell varies from $0.6 \mathrm{~km}$ at $2.6 \mathrm{GHz}$ to $1.4 \mathrm{~km}$ at $900 \mathrm{MHz}$. For the urban dense area, according to $[13,14]$ a $0.57 \mathrm{~km}$ range is considered for the MaBS. Nevertheless, according to [39], the IMT-Advanced UMa model considers inter-site distance of $0.5 \mathrm{~km}$ and UMi O-to-I (outdoor-to-indoor) model considers inter-site distance of $0.2 \mathrm{~km}$, also taking into account the $20 \mathrm{~dB}$ loss through walls under its relevant path loss model. Consequently, we assume $0.25 \mathrm{~km}$ cell range for the 4G LTE-A MaBS sites and $0.1 \mathrm{~km}$ cell range for the 4G LTE-A MiBS and 5G mmW MiBS deployment because we assume it is deployed according to the 3GPP Urban Micro (UMi) model [39], too. This is in line with the elaborations in [3-5], where authors also estimate $0.1 \mathrm{~km}$ range for 3 -sector $5 \mathrm{G} \mathrm{mmW} \mathrm{MiBS}$ site. According to [16], we model the aggregated capacity of the system, $T_{s y s t}$, as follows:

$$
T_{\text {ssst }}=W \cdot N_{\text {site }} \cdot N_{\text {cell }} \cdot S_{\text {eff }}
$$

where $W$ is allocated bandwidth in $\mathrm{MHz}, N_{\text {site }}$ is the total number of BS/AP sites within the system coverage area, $N_{\text {cell }}$ is the number of cells and $S_{\text {eff }}$ is the average cell spectral efficiency in bps/Hz/cell. Considering the best antenna configuration, based on [40] the average cell spectral efficiency for LTE-A is 4.2 and $3.8 \mathrm{bit} / \mathrm{s} / \mathrm{Hz} /$ cell for the microcellular and base coverage urban environments, respectively. The cell edge spectral efficiency equals to 0.15 and 0.10 for the FDD UMi and FDD Uma (20 MHz carrier), respectively. The empirical path-loss results for the $\mathrm{mmW}$ systems obtained for the $100 \mathrm{~m}$ distance between the end nodes, are mostly close to be represented by the Free-space loss model presented in [8] as follows:

$$
P L_{F S, A B}=112.4+20 \log _{10}\left(f_{c}\right)+20 \log _{10}(d)
$$

where, $f_{c}$ is the carrier frequency in $\mathrm{GHz}$, and $d$ is the distance in $\mathrm{km}$.

Based on the empirical results of [3-6], for the $\mathrm{mmW}$ we consider average cell spectral efficiency of $3.34 \mathrm{bit} / \mathrm{s} / \mathrm{Hz} /$ cell and $2.93 \mathrm{bit} / \mathrm{s} / \mathrm{Hz} / \mathrm{ce}$ ll when using $28 \mathrm{GHz}$ and $73 \mathrm{GHz}$ carriers, respectively. In this case, the 5\% cell edge rates are 52.28 Mbps and $24.08 \mathrm{Mbps}$ when using $28 \mathrm{GHz}$ and $73 \mathrm{GHz}$ single carriers, respectively. Regarding the bandwidth, for the 4G LTE-A RAT we consider for each bandwidth chunks of 10 or $20 \mathrm{MHz}$ and for the $5 \mathrm{G} \mathrm{mmW}$ system in line with [3,6] and [8], we consider the 50-50 UL-DL TDD split of the $1 \mathrm{GHz}$ bandwidth (or $500 \mathrm{MHz}$ chunk in DL). For the Wi-Fi coverage-capacity deployment options, we consider that according to [41] it is very difficult to exceed 50-60\% of the nominal bit rate of the underlying physical layer of Wi-Fi. According to [37], the IEEE 802.11ac products operating in the $5 \mathrm{GHz}$ band with $80 \mathrm{MHz}$, can deliver up to $1300 \mathrm{Mbps}$ (high end) at the physical layer up to $30 \mathrm{~m}$ coverage range. Related to IEEE $802.11 \mathrm{n}$, according to [9] this standard envisages $34.4 \mathrm{MHz}$ channel bandwidth at $5.2 \mathrm{GHz}$ carrier frequency with the maximum physical layer data rate of $288 \mathrm{Mbps}$. Based on the analysis in this section, Table 3 summarizes the coverage-capacity estimates related to all BS/AP classes enabled with different RATs considered. 
Table 3. Coverage and Capacity Performances for BSS/APS Classes Enabled with Different Rats and Placed Outside within Residential Area

\begin{tabular}{|c|c|c|c|c|c|}
\hline $\begin{array}{l}\text { BS/AP Class/ } \\
\text { RAT Parameter }\end{array}$ & $\begin{array}{l}\quad 4 \mathrm{G} \\
\mathrm{LTE}-\mathrm{A} \\
\mathrm{MaBS}\end{array}$ & $\begin{array}{l}\quad 4 \mathrm{G} \\
\text { LTE-A } \\
\text { MiBS }\end{array}$ & \begin{tabular}{cc}
\multicolumn{2}{c}{$5 \mathrm{G}$} \\
$\mathrm{mmW}$ \\
$\mathrm{S}$ & $\mathrm{MiB}$
\end{tabular} & $\begin{array}{c}\text { Wi-Fi } \\
\text { IEEE } \\
\text { 802.11ac AP }\end{array}$ & $\begin{array}{c}\text { Wi-Fi } \\
\text { IEEE } \\
802.11 n \text { AP }\end{array}$ \\
\hline Range $(\mathrm{km})$ & 0.25 & 0.10 & 0.10 & 0.03 & 0.03 \\
\hline Coverage $\left(\mathrm{km}^{2}\right)$ & 0.2 & 0.03 & 0.03 & 0.003 & 0.003 \\
\hline Sectors & 3 & 3 & 3 & 1 & 1 \\
\hline Carriers & 1 & 1 & 1 & 1 & 1 \\
\hline Bandwidth (MHz) & 20 & 20 & 500 & 80 & 34.4 \\
\hline Carrier $(\mathrm{GHz})$ & 2.6 & 2.6 & 28 & 5 & 5 \\
\hline $\begin{array}{l}\text { Av. Cell Spectral Eff. } \\
\text { (bps/Hz) }\end{array}$ & 3.8 & 4.2 & 3.38 & 16.25 & 8.37 \\
\hline Av. Cell Capac. (Mbps) & 76 & 76 & 1690 & 1300 & 228 \\
\hline Av. Site Capac. (Mbps) & 228 & 252 & 5070 & 1300 & 288 \\
\hline
\end{tabular}

\section{Incremental Cost Modeling}

Please avoid using bit-mapped fonts if possible. True-Type 1 fonts are preferred. Based on demanded capacity and coverage targets elaborated previously, it is forthright to estimate the number of BS/AP sites $\left(N_{B S / A P}\right)$ which multiplied with CAPEX figures per BS/AP class $\left(C_{B S / A P}\right)$, very closely yields the total CAPEX needed for deployment of particular HetNet layout, or:

$$
\text { CAPEX }_{\text {HETNET }} \approx C_{B S / A P} \cdot N_{B S / A P}
$$

A BS of class $i$ is associated with cost $c_{i}$, including capital expenditures (CAPEX) and operating costs (OPEX). We consider the BS equipment, BS (site) installation \& buildout, backhaul transmission equipment and Radio Network Controller (RNC) equipment as BS related CAPEX items and electric power, operation \& maintenance, site lease and backhaul transmission lease as BS related OPEX items. We base our cost structure modelling to the methodology developed in $[9,15,21,22]$. The total network cost comprising of radio access network $\left(C_{R A N}\right)$ related costs, business-driven $\left(C_{B U S / C O M}\right)$ costs and costs for spectrum license $\left(C_{S P E C}\right)$ normalized per unit area $\left(A_{S Y S}\right)$, can be presented as follows:

$$
C_{\text {TOT }}=C_{\text {RAN }}+C_{\text {BUS / COM }}+\frac{C_{S P E C}}{A_{S Y S}} \quad\left[\frac{\cos t}{\text { area }}\right]
$$

In this chapter, we diminish the spectrum and business related costs as sunk cost. The present values of the RAN related cost or the total accumulated Net Present Value of the network $\left(N P V\left(C_{T O T}\right)\right)$ represents the sum of the yearly cost in terms of annualized CAPEX and OPEX, which are discounted by discount rate of $12.5 \%$ (we equalize the discount rate to the Weighted Average Cost of Capital - WACC [17]), for the network life cycle of $\mathrm{K}=10$ years, or:

$$
\begin{array}{r}
N P V\left(C_{\text {TOT }}\right)=N P V(\text { OPEX })+N P V(\text { Ann CAPEX }) \\
N P V(\text { OPEX })=\sum_{i=0}^{K-1} \frac{\text { OPEX }{ }^{(i)}}{(1+\text { WACC })^{i}} \\
\text { OPEX } \quad{ }^{(i)}=\sum_{j} N_{j}^{(i)} c_{j}^{\text {OPEX }}\left(1+p_{j}^{\text {OPEX }}\right)^{i-1}
\end{array}
$$




$$
\begin{aligned}
& N P V(\text { Ann .CAPEX })=\sum_{i=0}^{K-1} \frac{A n n \cdot C A P E X \quad{ }^{(i)}}{(1+W A C C)^{i}} \\
& \text { Ann.CAPEX }{ }^{(i)}=\sum_{j} I_{j}^{(i)} \cdot \gamma \\
& I_{j}^{(i)}=\sum_{j} M_{j}^{(i)} c_{j}^{C A P E X}\left(1+p_{j}^{C A P E X}\right)^{i-1} \\
& \gamma=\frac{W A C C \quad(1+W A C C \quad)^{n}}{(1+W A C C \quad)^{n}-1}
\end{aligned}
$$

Within the above equations Ann.CAPEX represents the annualized CAPEX, $I_{j}^{(i)}$ represents the investment in asset type " $j$ " $\in$ \{equipment of particular BS or AP class, transmission links, backhaul equipment... $\}$ in year " $i$ ", and $\gamma$ the parameter which is annualizing the present value of the capital investments with discount rate equal again to $W A C C$ with " $n$ " number of years over which the value is annualized. The other symbols used have the following meaning: $N_{j}^{(i)}$ - number of operated items of type " $j$ " in year " $i$ ",

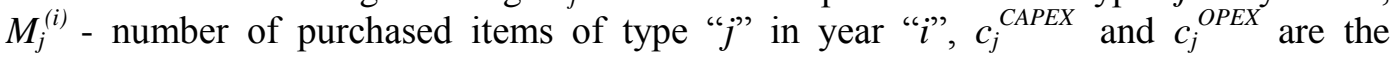
associated per unit investment and operating cost, respectively, for each asset " $j$ " in the initial year, and $p_{j}^{C A P E X}$ and $p_{j}^{O P E X}$ denote the respective yearly price trends.

According to $[9,14]$, we divide the cost structure of RAN in two groups: the first related to the costs for radio equipment, and the second combining the costs for the BS site deployment and transmission. In line with [9], [17], in this study new base stations and upgrades of existing sites are deployed over time, because of what an annual price erosion should be considered for base station equipment. Regarding the $\mathrm{mmW}$ based deployments, it should be noted that such hardware is far from commercialization so the price level is quite uncertain. Nevertheless, due to general declining trend of the prices for the BS related hardware, we expect that the radio equipment for the $5 \mathrm{G} \mathrm{mmW}$ sites to be lower compared to 4G LTE-A RAT. Thus, considering the 5\% yearly price erosion, we assume that the $5 \mathrm{G} \mathrm{mmW}$ MiBS radio equipment supporting 3 sectors and 1 carrier, will be around 12.8 $\mathrm{k} €$ for the reference year 2021. Quite opposite, because of the need to support the RAN capacity advances, we assume the transport cost for the typical PTP backhaul infrastructure to have an increasing trend. The findings related to the cost items (CAPEX and OPEX) for 4G LTE-A MaBS, 4G LTE-A MiBS, 5G mmW MiBS sites and Wi-Fi AP sites are elaborated in details in our contribution [30] which is based on the cost items analysis from [9, 13, 14, 17, 42, 43].

As summary, Table 4 contains the cost drivers with respect to CAPEX, OPEX and total discounted costs for each of the newly deployed BS/AP classes enabled with various RATs. 


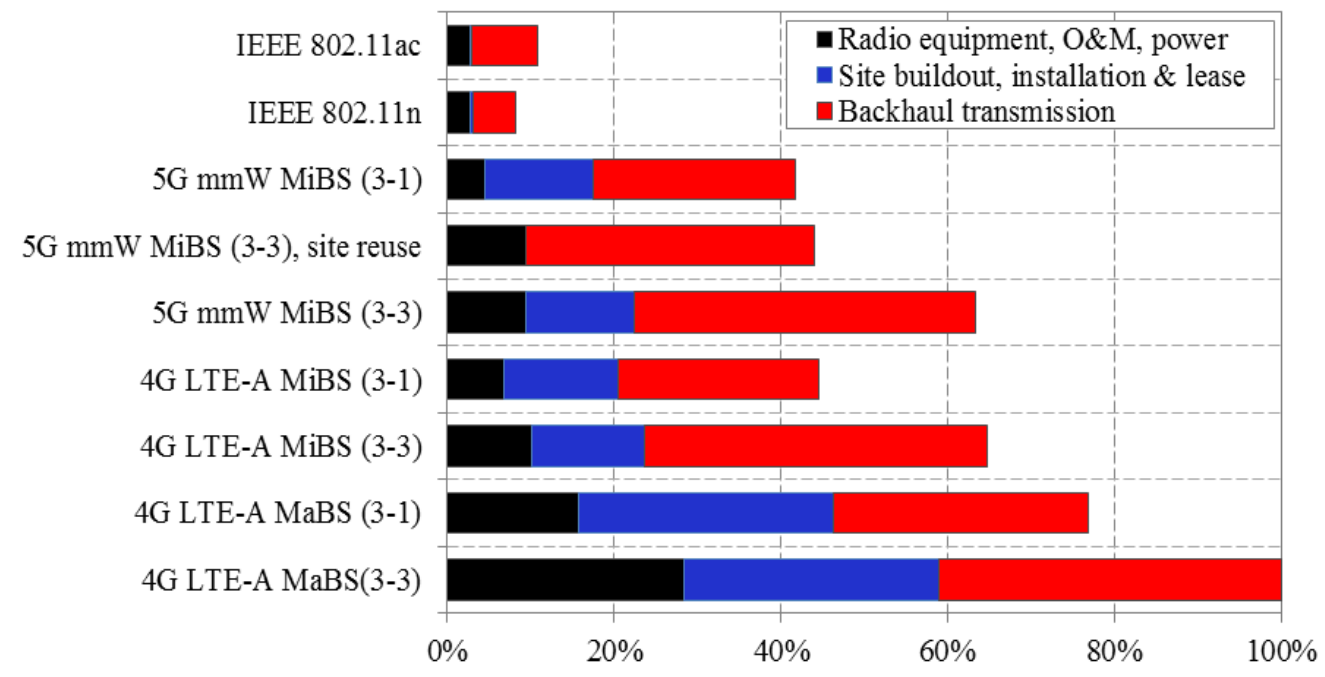

Figure 2. Resulting Total Discounted Cost Structure of BP/AP Classes

Furthermore, Figure 2 depicts the total resulting discounted costs of the considered layout, clustered by related expenditures of radio equipment, site and transmission. Based on this cost modeling approach, the primary goal is to answer the question, which type of capacity expansion would minimize aggregate incremental cost or the total cost of ownership (TCO) (for an expected traffic growth). According to [17], TCO should be used for offering a clear picture over the total involved costs for the entire studied period by taking into account the total expenses when running a network including acquisition price and yearly operating \& maintenance costs.

Table 4. Cost Drivers with Respect to CAPEX and OPEX for Newly BS/AP Classes Deployed in Concrete Year (The Reuse of the Site is Indicated)

\begin{tabular}{|c|c|c|c|c|c|c|}
\hline New sites & \multicolumn{3}{|c|}{ CAPEX } & \multicolumn{3}{|c|}{ OPEX } \\
\hline BS/AP Class/RAT & $\begin{array}{l}\text { Radi } \\
\text { o Eq. }\end{array}$ & $\begin{array}{l}\text { Tra } \\
\text { ns. }\end{array}$ & Site & $\begin{array}{l}\text { Tra } \\
\text { ns. }\end{array}$ & te ${ }^{\mathrm{Si}}$ & $\begin{array}{l}\text { O\& } \\
\text { M, } \\
\text { Power }\end{array}$ \\
\hline $\begin{array}{l}\text { 4G LTE-A MaBS - } 3 \text { sector and } 3 \\
\text { carriers (2017) }\end{array}$ & 30.0 & 30.0 & 30.0 & 15.0 & $\begin{array}{r}1 \\
0.0\end{array}$ & 9.0 \\
\hline $\begin{array}{l}\text { 4G LTE-A MaBS - } 3 \text { sector and } 1 \\
\text { carrier (2017) }\end{array}$ & 10.0 & 30.0 & 30.0 & 10.0 & $\begin{array}{r}1 \\
0.0\end{array}$ & 6.0 \\
\hline $\begin{array}{l}\text { 4G LTE-A MiBS (2017) - } 3 \text { sector } \\
\text { and } 3 \text { carriers }\end{array}$ & 15.0 & 30.0 & 10.0 & 15.0 & 0. & 2.5 \\
\hline $\begin{array}{l}\text { 4G LTE-A MiBS (2017) - } 3 \text { sector } \\
\text { and } 1 \text { carrier }\end{array}$ & 5.0 & 10.0 & 10.0 & 10.0 & 0. & 1.5 \\
\hline $\begin{array}{l}5 \mathrm{G} \mathrm{mmW} \text { MiBS (2021) - } 3 \text { sector } \\
\text { and } 3 \text { carriers }\end{array}$ & 12.8 & 30.0 & 8.0 & 15.0 & 5. & 2.5 \\
\hline $\begin{array}{l}5 \mathrm{G} \text { mmW MiBS (2021) - } 3 \text { sector } \\
\text { and } 3 \text { carriers (site reuse) }\end{array}$ & 12.8 & 30.0 & 0.0 & 15.0 & 0. & 2.5 \\
\hline $\begin{array}{l}5 \mathrm{G} \mathrm{mmW} \text { MiBS (2021) - } 3 \text { sector } \\
\text { and } 1 \text { carrier }\end{array}$ & 4.3 & 10.0 & 8.0 & 10.0 & 5. & 1.5 \\
\hline $\begin{array}{l}\text { WLAN 802.11ac AP (2019) - } 1 \\
\text { sector and } 1 \text { carrier }\end{array}$ & 3.4 & 5.0 & 1.0 & 3.0 & 0 & 0.75 \\
\hline $\begin{array}{l}\text { WLAN 802.11n AP (2019) - } 1 \\
\text { sector and } 1 \text { carrier }\end{array}$ & 3.8 & 3.0 & 1.0 & 2.0 & 0 & 0.75 \\
\hline
\end{tabular}

In this study, we differentiate the considered HetNet expansion strategies in Section 4, also based on the choice if the new BSs will be used or upgrades of the existing sites will be deployed over time. Regarding the placement of the totally new sites, BS/AP prices 
have been adjusted based on the general price erosion assumed for equipment. Transmission costs are considered to be stable or higher across the years due to the higher peak data rate required in the future. For the upgrade of the existing site, we consider the following options:

1. Denser layout, assuming building of new sites (next to the existing sites) with the same or new RAT as previous for what new antenna system (radio equipment) is installed, but however, the fiber backhaul already is in place through the previous build site. Thus, for the incremental CAPEX, the radio equipment and site related costs are only considered. These upgrades add to all OPEX items.

2. Existing base stations are enhanced and additional base stations are, deployed in hot spots, in which case addition of base stations with new RAT is deployed at regular sites supporting previous RAT (site reuse). A new fiber backhaul is thus installed, which adds to both capital (all items) and operational (only to transmission) expenditures.

3. Upgrade with new RAT (replacement of previous RAT used in hot spot layer) or upgrade of the existing RAT (adding additional carriers), through upgrade of BS platform assuming new radio equipment and software upgrade, what could require increased backhaul transmission capacity or utilization of the fiber backhaul that is already in place. All this adds to both CAPEX (all items) and OPEX (only to transmission).

In line with this analysis, CAPEX and OPEX for these units are calculated based on assumptions for a concrete reference year (either year 2017 or 2021 as shown in Table 4).

Table 5. Estimates on the Incremental Cost per BS/AP Class for Upgrades of Existing Sites, in the Reference Year, for Particular Expansion Strategy

\begin{tabular}{|c|c|c|c|c|c|c|}
\hline \multirow{2}{*}{$\begin{array}{c}\text { BS/AP Class/RAT - } \\
\text { Upgrades of existing sites }\end{array}$} & \multicolumn{3}{|c|}{ CAPEX } & \multicolumn{3}{|c|}{ OPEX } \\
\hline & $\begin{array}{c}\text { Radio } \\
\text { Equipment }\end{array}$ & $\begin{array}{r}\text { Trans } \\
\text { mi-ssion }\end{array}$ & $\mathrm{e}^{\text {Sit }}$ & $\begin{array}{l}\text { Transm } \\
\text { i-ssion }\end{array}$ & Site & $\begin{array}{l}\text { O\& } \\
\text { M, } \\
\text { Power }\end{array}$ \\
\hline $\begin{array}{l}\text { Dense 4G LTE-A MaBS } \\
-3 \text { sector and } 1 \text { carrier }\end{array}$ & 10.0 & 0.0 & $\begin{array}{l}30 . \\
0\end{array}$ & 10.0 & $\begin{array}{l}10 . \\
0\end{array}$ & 6.0 \\
\hline $\begin{array}{l}\text { Dense 4G LTE-A MaBS } \\
-3 \text { sector and } 3 \text { carriers }\end{array}$ & 30.0 & 0.0 & $\begin{array}{l}10 . \\
0\end{array}$ & 15.0 & 0.0 & 6.0 \\
\hline $\begin{array}{l}\text { 4G LTE-A MaBS - } 3 \\
\text { sector and } 1 \text { carrier, upgrade } \\
\text { with additional carrier }\end{array}$ & 10.0 & 0.0 & 0.0 & 10.0 & 0.0 & 0.0 \\
\hline $\begin{array}{l}\text { 4G LTE-A MiBS - } 3 \\
\text { sector and } 1 \text { carrier, upgrade } \\
\text { with additional carrier }\end{array}$ & 5.0 & 0.0 & 0.0 & 10.0 & 0.0 & 0.0 \\
\hline $\begin{array}{l}5 \mathrm{G} \text { mmW MiBS }-3 \\
\text { sectors and } 1 \text { carrier } \\
\text { (upgrade with site reuse) }\end{array}$ & 4.3 & 5.0 & 0.0 & 10.0 & 5.0 & 0.0 \\
\hline $\begin{array}{l}5 \mathrm{G} \text { mmW MiBS }-3 \\
\text { sectors and } 1 \text { carrier } \\
\text { (upgrade of BS platfrom for } \\
\text { hot spot) }\end{array}$ & 4.3 & 5.0 & 0.0 & 10.0 & 2.0 & 0.0 \\
\hline $\begin{array}{l}5 \mathrm{G} \text { mmW MiBS }-3 \\
\text { sector and } 1 \text { carrier, upgrade } \\
\text { with additional carrier }\end{array}$ & 4.3 & 0.0 & 0.0 & 10.0 & 0.0 & 0.0 \\
\hline $\begin{array}{l}\text { Dense } 5 \mathrm{G} \text { mmW MiBS } 3 \\
\text { sectors and } 3 \text { carriers }\end{array}$ & 12.8 & 0.0 & 8.0 & 10.0 & 5.0 & 2.50 \\
\hline
\end{tabular}

Table 5 summarizes the exact assumptions on incremental costs per unit for each of the particular expansion strategies considered in the Table 2 (M-RAT, CEDE-I and CEDE-II). 


\section{Findings of the Incremental Cost Analysis}

Based on the previous inputs, in this section we calculate the total cost of ownership (TCO) of the considered expansion strategies (M-RAT, CEDE-I and CEDE-II) for the three traffic growth scenarios (MBB LIN LOW, MBB LIN HIGH and BB REP SIGMO). Saying different, the cost analysis is based on comparing the total cost for each deployment in order to meet the targeted capacity demand for particular year. The related discounted incremental costs are given in Figure 3.

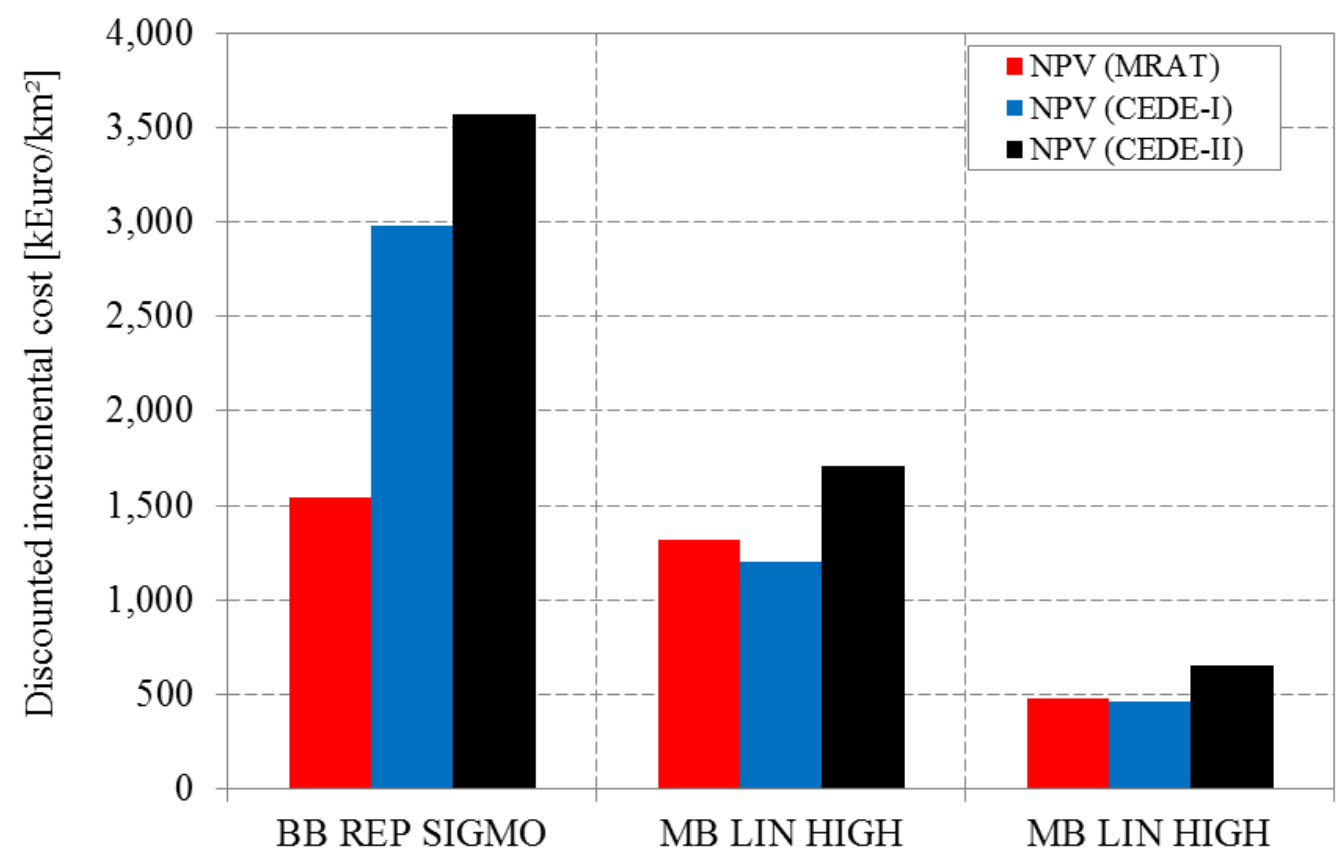

\section{Figure 3. The Net Present Value of Tte Discounted Incremental Cost for the Expansion Strategies Related to Various Traffic Growth Scenarios}

The results show that the total discounted incremental cost is approximately the same in case of the MBB LIN HIGH and MBB LIN LOW scenarios, for the CEDE-II and MRAT expansion strategies, or around 1.2 Mil $€$ per $\mathrm{km}^{2}$ and 0.5 Mil $€$ per $\mathrm{km}^{2}$, respectively. For these two traffic scenarios, the cellular development strategy using dense MaBSs layout (CEDE-II) is more expensive because of the higher unit cost for the macro layer. This is also valid for the most capacity demanding BB REP SIGMO traffic growth scenario, which also has the highest differences between NPV values of all three traffic scenarios, or CEDE-II is higher for around $15 \%$ and $130 \%$ than the NPV values of the total discounted incremental cost of CEDE-I and M-RAT, respectively. For the BB REP SIGMO scenario, the difference between CEDE-II and M-RAT is evident (or around $100 \%$ ). The reason for this is that in case of CEDE-II the OPEX contribution is higher compared to the M-RAT scenario. Also, it can be seen that by comparing the BB REP SIGMO and MBB LIN HIGH traffic scenarios, the discounted incremental cost is approximately $15 \%, 150 \%$, and $105 \%$ higher for the BB REP SIGMO traffic scenario in case of the M-RAT, CEDE-I and CEDE-II, respectively. 


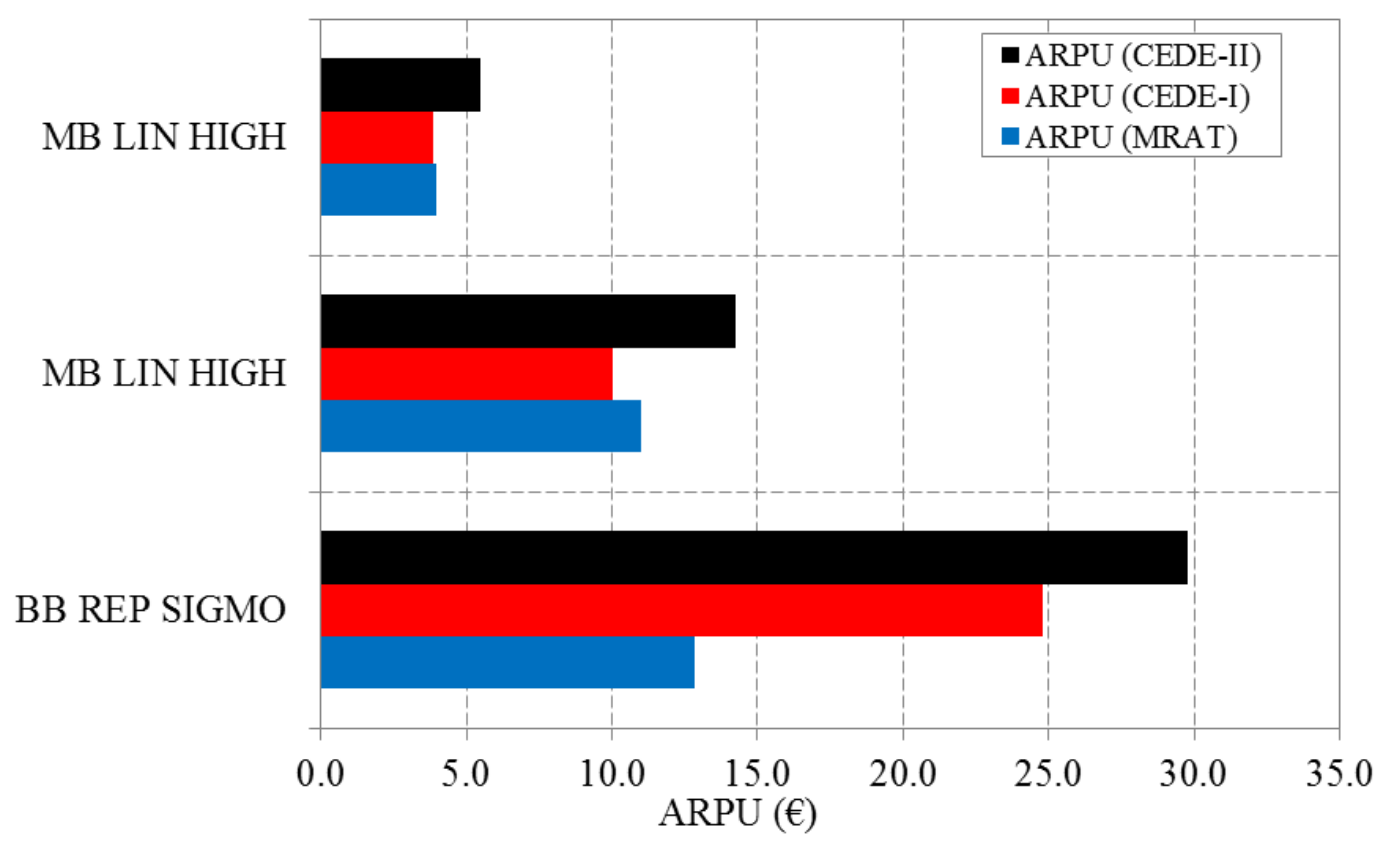

\section{Figure 4. The Needed Extra ARPU for Positive NPV Related to Different Expansion Strategies and Traffic Growth Scenarios}

Furthermore, we calculate the " $\Delta$ " or the increased level of average revenue per user (ARPU) per month that will be sufficient to ensure the positive NPV. Thus, based on the results of Figure 3, the Figure 4 contains the levels of minimum needed extra monthly ARPU to make the positive NPV. Thus, positive NPV would be reached at an increased ARPU of around $25.0 € /$ month in the case of traffic demand as per BB REP SIGMO scenario and CEDE-I expansion strategy or approximately with 15.0 /month if the traffic increases per MBB LIN HIGH scenario with the CEDE-II expansion strategy. The tolerable and most balanced ARPU increase of around $12.8 € /$ month can be reached in case of SIGMOID traffic scenario with the M-RAT expansion strategy. Again, this was calculated at a $12.5 \%$ discount rate and the same equal number of 10,000 users over the studied period of 9 years.

Related to the total number of used BS/AP sites in hot spots per $\mathrm{km}^{2}$, the results for each of the considered expansion strategy and traffic growth scenarios is shown in Table 6. In particular, a large number of $4 \mathrm{G}$ LTE-A MaBSs and MiBSs are needed to support the offered traffic volumes in the years 2018-2020 especially for CEDE-I and CEDE-II expansion strategies. Also, this is relevant for the Wi-Fi APs for the M-RAT expansion path in case of the BB REP SIGMO scenario. Still, almost in all cases a massive deployment is minimized with the introduction of the $5 \mathrm{G} \mathrm{mmW}$ MiBS layer.

The aggregate incremental (non-discounted) expenditures representing the TCO per year are presented in Figure 5 for the three traffic growth scenarios (a), b), and c)). The TCO for the final year (2025) shows the total expenditures during the whole period under study.

What can be first noticed is that in the traffic scenario which is most capacity driven, or the BB REP SIGMO scenario, the annual expenditures (TCO) are significantly lower for the M-RAT expansion strategy. This is especially valid for the medium and the long term period. Even more, it can be seen that the total cost over almost the whole period is similar for the M-RAT scenario in case of the BB REP SIGMO and MBB LIN HIGH traffic scenarios, what gives more confidence to the MNO regardless of the traffic growth pattern. 
Table 6. Number of BS/AP Site in the Hot Spot Layer per $\mathbf{k m}^{2}$

\begin{tabular}{|c|c|c|c|c|c|c|c|c|c|}
\hline Year & $7^{201}$ & $8^{201}$ & $9^{201}$ & $0^{202}$ & $1^{202}$ & $2^{202}$ & $3^{202}$ & $\begin{array}{r}2 \\
024^{2}\end{array}$ & $25^{20}$ \\
\hline \multicolumn{10}{|c|}{ BB REP SIGMO Traffic Scenario } \\
\hline M-RAT & 2 & 34 & 6 & 12 & 30 & 13 & 7 & 6 & 6 \\
\hline CEDE-I & 2 & 11 & 40 & 68 & 30 & 13 & 7 & 6 & 6 \\
\hline CEDE-II & 6 & 30 & 74 & 79 & 30 & 13 & 7 & 6 & 6 \\
\hline \multicolumn{10}{|c|}{ MBB LIN HIGH Traffic Scenario } \\
\hline M-RAT & 4 & 7 & 1 & 2 & 4 & 4 & 5 & 9 & 18 \\
\hline CEDE-I & 4 & 3 & 4 & 10 & 4 & 4 & 5 & 9 & 18 \\
\hline CEDE-II & 10 & 7 & 7 & 12 & 4 & 4 & 5 & 9 & 18 \\
\hline \multicolumn{10}{|c|}{ MBB LIN LOW Traffic Scenario } \\
\hline M-RAT & 1 & 3 & 1 & 1 & 2 & 2 & 3 & 5 & 11 \\
\hline CEDE-I & 1 & 1 & 2 & 3 & 2 & 2 & 3 & 5 & 11 \\
\hline CEDE-II & 3 & 3 & 3 & 3 & 2 & 2 & 3 & 5 & 11 \\
\hline
\end{tabular}

Driven by the higher investments on the short run, and before 5G mmW RAT commercialization, it is clear that a strategy with cellular development driven by the macro layer (CEDE-I) will have the highest TCO over the analyzed period, no matter of the traffic growth scenario. Also, the annual expenditures in the medium and long term are almost equal in case of the M-RAT and CEDE-II expansion strategies for the MBB LIN LOW traffic growth scenario. The reason for this could be found in the relatively lower expenditures driven by the 4G LTE-A MiBS or Wi-Fi in the short run, and in later stages by the low cost of $5 \mathrm{G} \mathrm{mmW}$ MiBS which is almost identical no matter that in case of CEDE-II the hot spot layer is replaced by the $5 \mathrm{G} \mathrm{mmW}$ MiBSs and in case of the MRAT strategy the number of sites are reused for the same $5 \mathrm{G}$ based layout.

Further, it is worth of consideration the aspect that in case of the BB REP SIGMO scenario, almost the same cost pattern can be identified between CEDE-I and CEDE-II expansion strategies, with higher annual expenditures of around 1.0 Mil $€$ for the CEDEII strategy due to the predominant macro layer. Lastly, we could indicate that until the appearance of the low-cost $\mathrm{mmW}$ based $5 \mathrm{G}$ technology that will surely diminish the higher expenditures occurring with 4G LTE-A MaBS sites, in the meantime Wi-Fi APs should be deployed at certain (or at the hot spot) locations as sufficient to respond to the area capacity values even in the mid-term.

\section{Conclusion}

In this article, we assess from techno-economic perspective few possible incremental deployment strategies for capacity expansion of MNOs, seeking to deploy future wireless HetNets capable to satisfy over time (2017-2025) increasing traffic volumes.

The findings show that considered capacity expansion paths at least by year 2025 would provide a different incremental cost for MNOs in the densely populated urban areas. In particular, on long rung there is high potential for capacity increase that could enable higher data rates per user, thanks to the huge amount of additional bandwidth laying in the $\mathrm{mmW}$ band of the frequency spectrum. Nevertheless, in the mid-term and before standardization and commercialization of the high capacity enabling RATs from the $5^{\text {th }}$ generation, MNOs need to satisfy the increasing data demand with mix of RATs. This would be especially valid for the hot spots, which could be complemented with the advanced Wi-Fi APs like IEEE 802.11ac.

For the short run, surprisingly the lower aggregated incremental cost can be achieved with the expansion strategy of cellular development assuming denser deployments with LTE-Advanced macro layer, compared to the case of adding additional MiBS sites. The reason for this could be found in the higher number of aggregated carriers in the case of 
4G LTE-A MaBSs by what higher capacity can be achieved with lower number of base stations. The capacity differences reflected in the different level of TCO are less evident in the cases when the traffic growth is liner.

Finally, we could conclude that one of the crucial uses for an incremental cost deployment study in practice would be to assess the economic feasibility of different business cases. With this regard, one may conclude that the traffic growth scenarios evaluated here can be maintained at tolerable incremental costs.

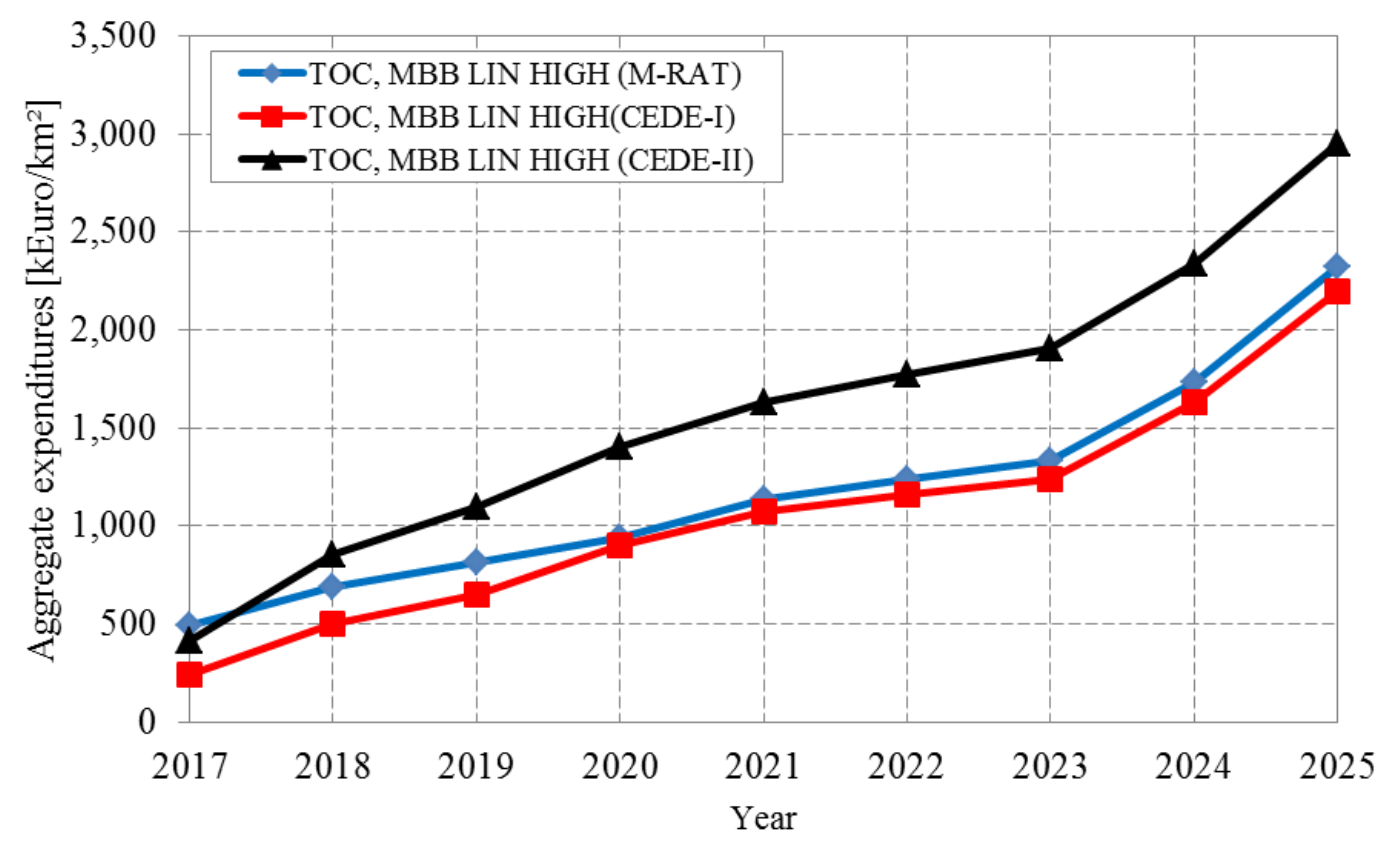

(a) Mobile Broadband Linear High Growth Traffic Scenario

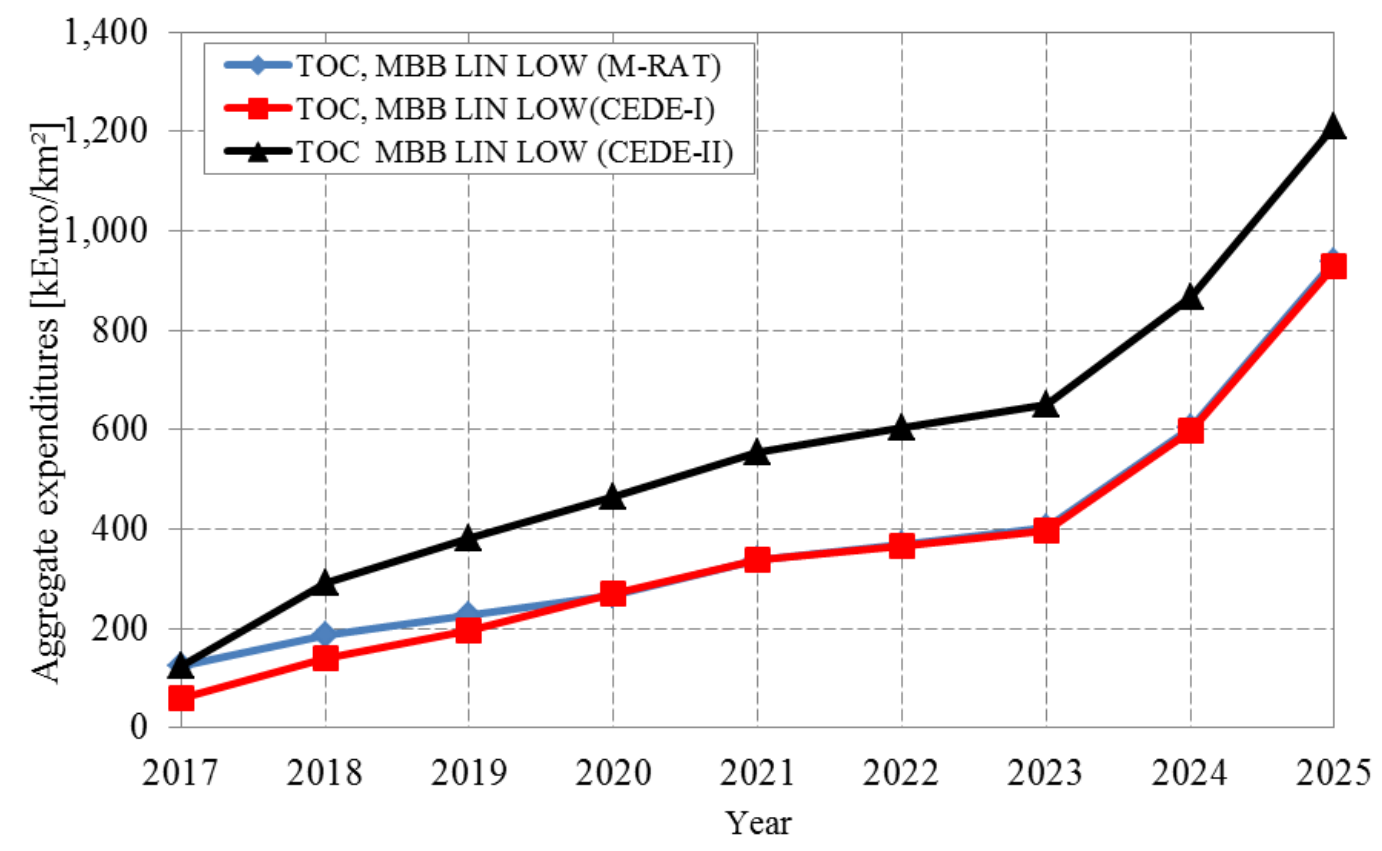

(b) Mobile Broadband Linear Low Growth Traffic Scenario 


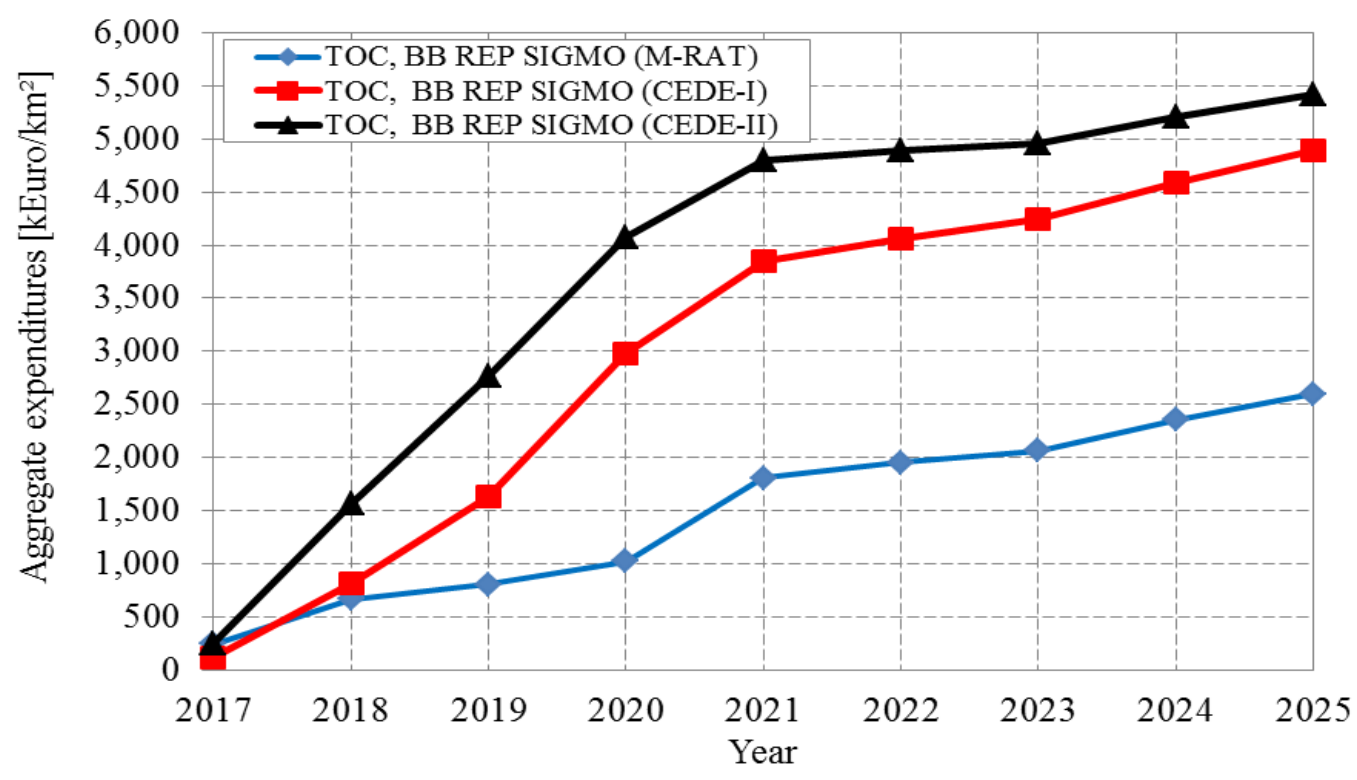

(c) Broadband Replacement Sigmoid Growth Traffic Scenario

\section{Figure 5. The Total Cost of Ownership (Non-Discounted) per Year for the Three Different Traffic Growth Scenarios (A), (B) and (C)}

\section{Acknowledgments}

We would like to express our sincere thanks to our families for their support.

\section{References}

[1] E. Hossain, "5G Cellular: Key Enabling Technologies and Research Challenges", Cornell University, arXiv:1503.00674, (2015) February.

[2] F. Boccardi, "Five disruptive technology directions for 5G", IEEE Comm. Magazine, (2014) February.

[3] M. R Akdeniz, "Millimeter Wave Channel Modeling and Cellular Capacity Evaluation", Cornell University Library. http://arxiv.org/abs/1312.4921, (2013) December.

[4] Z. Hang, "Indoor $28 \mathrm{GHz}$ Millimeter Wave Cellular Communication Measurements for Reflection and Penetration Loss in and around Buildings in New York City", 2013 IEEE ICC., (2013) June.

[5] T. S. Rappaport, "Millimeter Wave Mobile Communications for 5G Cellular: It Will Work!", IEEE Access Journal, vol. 1, (2013), pp. 335-349.

[6] S. Rangan, "Millimeter Wave Cellular Wireless Networks: Potentials and challenges", Proceedings of the IEEE, vol. 102, no. 3, (2014) March, pp. 366-385.

[7] J.N. Murdock, "A 38 GHz Cellular Outage Study for an Urban Outdoor Campus Environment", in Proc. IEEE Wireless Commun. Netw. Conf., Apr. (2012), pp. 3085-3090.

[8] F. Khan and Z. Pi, "Millimeter-wave Mobile Broadband (MMB): Unleashing 3-300GHz Spectrum", in Proc. IEEE Sarnoff Symposium, (2011) March.

[9] K. Johansson, "Cost Effective Deployment Strategies for Heterogeneous Wireless Networks", PhD Dissertation. The Royal Institute of Technology, Stockholm, (2007).

[10] K. Johansson , "Relation between base station characteristics and cost structure in cellular systems", Proceedings of IEEE PMRC, (2004).

[11] K. Johansson and A. Furuskär, "Cost efficient capacity expansion strategies using multi-access networks", In Proc. IEEE VTC, (2005) May.

[12] K. Johansson, J. Zander, and A. Furuskär, "Modelling the cost of heterogeneous wireless access networks", Int. J. Mobile Network Design and Innovation 01/2007, vol. 2, no. 2, (2007), pp. 58-66.

[13] J. Markendahl and O. Mäkitalo, "A comparative study of deployment options, capacity and cost structure for macrocellular and femtocell networks", in Proceedings of (IOFC 2010), Istanbul, (2010) September.

[14] J. Markendahl, "Mobile Network Operators and Cooperation", PhD Dissertation. The Royal Institute of Technology, Stockholm, (2011).

[15] Z. Frias and J. Pérez, "Techno-economic analysis of femtocell deployment in long-term evolution networks", EURASIP Journal on Wireless Communications and Networking (2012), pp. 2012:288 
[16] B. Mölleryd, J. Markendahl, and O. Mäkitalo, "Mobile Broadband Expansion Calls for More Spectrum or Base Stations", European Regional ITS Conference, Copenhagen, (2010) September, pp. 13-15.

[17] R. Popescu, "Complementing macrocell deficits with either smallcells or Wi-Fi-willingness to choose based on the cost-capacity analysis", 24th European Regional Conference of the International Telecommunication Society, Florence, Italy, (2013) October, pp. 20-23.

[18] J. Markendahl, "Business Innovation Strategies to Reduce the Revenue Gap for Wireless Broadband Services", Journal COMMUNICATIONS \& STRATEGIES, no. 75, (2009) 3rd Q, p. 35.

[19] D. H. Kang, K. W. Sung and J. Zander, "Cost Efficient High Capacity Indoor Wireless Access: Denser Wi-Fi or Coordinated Pico-cellular?", Cornell University Library, (2012) November.

[20] B.G. Molleryd, "Spectrum valuation derived from network deployment and strategic positioning with different levels of spectrum in $800 \mathrm{MHz}$ ", ITS bi-annual conference, Tokyo, (2010) June.

[21] Widaa, "Toward capacity-efficient, cost-efficient and power efficient deployment strategy for indoor mobile broadband", 24th ERCITS Conference, Florence, Italy, (2013) October, pp. 20-23.

[22] Awadelkarim, "Interplay between cost, capacity and power consumption in heterogeneous mobile networks", 21st International Conference on Telecommunications (ICT), Lisbon (2014), May 4-7.

[23] Tombaz, "Is Backhaul Becoming a Bottleneck for Green Wireless Access Networks?" 2014 IEEE International Conference on Communications (ICC) 2014, Sydney, (2014), June 10-14.

[24] Mahloo, "Cost Modeling of Backhaul for Mobile Networks", IEEE ICC 2014, Sydney, (2014) June.

[25] V. Nikolikj and T. Janevski, "State-of-the-art comparative cost modeling of heavily-loaded wireless heterogeneous networks", $4^{\text {th }}$ International Conference VITAE, Aalborg, Denmark, (2014) May 11-14, pp. 1-5.

[26] V. Nikolikj and T. Janevski, "Cost Modeling of Advanced Heterogeneous Wireless Networks under Excessive User Demand", $12^{\text {th }}$ International Conference, WWIC 2014, Paris, France, in Proc. Wired/Wireless Internet Communications, Lecture Notes in Computer Science, A. Mellouk (Eds) Ed. New York: Springer International Publishing, vol. 8458, (2014) May 26-28, pp. 68-81.

[27] V. Nikolikj and T. Janevski, "Applicable cost modeling of LTE-Advanced and IEEE 802.11ac based heterogeneous wireless access networks". In Proceedings of AICT 2014, the 10th advanced international conference on telecommunications, Paris, France, July 20-24, 2014. Published in IARIA, 2014 International Journal on Advances in Telecommunications: (2014) July 20-24, pp. 125-131.

[28] V. Nikolikj and T. Janevski, "A comparative cost-capacity modeling of wireless heterogeneous networks, implemented within the $0.7 \mathrm{GHz}, 2.6 \mathrm{GHz}, 5 \mathrm{GHz}$ and $28 \mathrm{GHz}$ bands". IEEE International conference on ultra-wideband (ICUWB), Paris, France, (2014) September 1-3, pp. 489-494.

[29] V. Nikolikj and T. Janevski, "A Cost Modeling of High-Capacity LTE-Advanced and IEEE 802.11ac based Heterogeneous Networks, Deployed in the $700 \mathrm{MHz}, 2.6 \mathrm{GHz}$ and $5 \mathrm{GHz}$ Bands", 4th International conference on selected topics in Mobile and Wireless Networking (MoWNet '2014), Rome, Italy, Sep 08-10, 2014, in Elsevier Proc. Procedia Computer Science, vol. 40, (2014), pp. 49-56.

[30] V. Nikolikj and T. Janevski, "State-of-the-Art Business Performance Evaluation of the Advanced Wireless Heterogeneous Networks to be Deployed for the "TERA Age", Wireless Personal Communications, Special Issue on "Recent Advances in Mobile and Wireless Networks", D.J. Deng et al (Eds), Springer US, Science+Business Media New York, vol. 84, Issue 3, (2015) October, pp 22412270 ,.

[31] INSEE-French National Statistic Agency, retrieved September 15, (2015) from http://www.insee.fr/en/.

[32] K. Sumit (ed). Handbook of Telecommunications Economics, Technology evolution and the Internet. Elsevier North-Holland, vol. 2, (2005).

[33] D. Lee, "Induced Traffic and Induced Demand. Transportation Research Record", vol. 1659, (1999), pp.68-75.

[34] B. Williamson, "Do you need a mobile data forecast to estimate spectrum demand?", Plum Insight, (2014) June.

[35] H. Gruber, "The Economics of Mobile Telecommunications", Cambridge University Press, $1^{\text {st }}$ edition, (2005).

[36] EARTH Deliverable D2.3, "Energy efficiency analysis of the reference systems, areas of improvements and target breakdown", (2012) Jan.

[37] Cisco, "Visual Networking Index: Global Mobile Data Traffic Forecast Update", (2015) February, pp. 2014-2019.

[38] H. Holma, A. Toskala and P. Tapia (ed), "HSPA+ Evolution to Release 12: Performance and Optimization, John Wiley \& Sons", (2014).

[39] Report ITU-R M.2135-1, "Guidelines for evaluation of radio interface technologies for IMT-Advanced", (2009).

[40] ETSI TR 136913 V10.0.0, LTE: ETSI, (2011) April.

[41] Y. Xiao, "IEEE 802.11n: Enhancements for higher throughput in wireless LANs", Wireless Communications, IEEE, vol. 12 , no. 6, (2005), pp. 82-91.

[42] G. Blennerud, "Don't worry-Mobile broadband is profitable", Ericsson Business review, no. 2, (2009).

[43] E. Perahia and M.X. Gong, "Gigabit wireless LANs: an overview of IEEE 802.11ac and 802.11ad". Mobile Computing and Communications Review, (2011) January. 


\section{Authors}

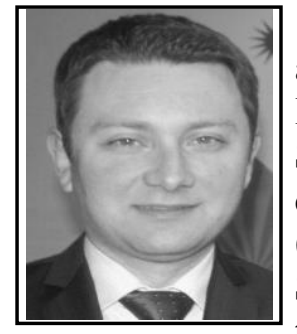

Vladimir Nikolikj, Author's profile. received the B.Sc. (2003) and M.Sc. (2007) degrees from Faculty of Electrical Engineering and Information Technologies, University "Ss Cyril and Methodius", Skopje, Macedonia, where he currently finalizing his $\mathrm{PhD}$ dissertation at the Institute of Telecommunications. He owns M.B.A. (2009) degree from the University Institute Kurt Bosch in Sion, Switzerland, too. He has more than 12 years working experience in the Macedonian subsidiaries of the international telecommunications companies. He is author of numerous journal articles and book chapters. His research interests include multi-RAT and multi-media network dimensioning, business development and EC ICT regulation.

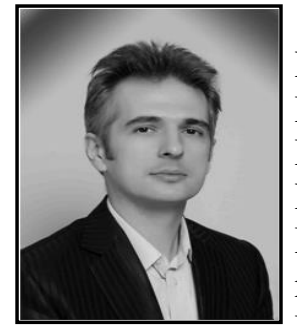

Toni Janevski, Ph.D., is a Full Professor at the Faculty of Electrical Engineering and Information Technologies, Ss. Cyril and Methodius University, Skopje, Macedonia. He received his Dipl. Ing., M.Sc. and Ph.D. degrees in electrical engineering all from Faculty of Electrical Engineering and Information Technologies, Ss. Cyril and Methodius University in Skopje, in 1996, 1999 and 2001, respectively. In the past, during 1996-1999 he has worked for the Macedonian mobile operator Mobimak (currently T-Mobile, Macedonia), contributing to the planning, dimensioning and implementation of the first mobile network in Macedonia. From 1999 he is with Faculty of Electrical Engineering and Information Technologies in Skopje. In 2001 he has conducted research in optical communications at IBM T.J. Watson Research Center, New York. During 2005-2008 he was an elected member of the Commission of the Agency for Electronic Communications (AEC) of the Republic of Macedonia. During the periods 2008-2012 and 2012-2016 he is an elected member of the Senate of the Ss. Cyril and Methodius University in Skopje. In 2009 he has established Macedonian ITU (International Telecommunication Union) Centre of Excellence (CoE) as part of the Europe's CoE network, and serves as its head/coordinator since than. He is the author of the book titled "Traffic Analysis and Design of Wireless IP Networks", which is published in 2003 by Artech House Inc, USA. Also, he is the author of the book "Switching and Routing", written in Macedonian language, published in September 2011 by the Ss. Cyril and Methodius University in Skopje. In 2012 he has won "Goce Delchev" award, the highest award for science in the Republic of Macedonia. Also, he received Best Scientists Award of the Ss. Cyril and Methodius University in Skopje for 2013. In April 2014 has appeared his second worldwide book titled "NGN Architectures, Protocols and Services", published by John Wiley \& Sons, UK. In July 2015 appeared his book "Internet Technologies", written in Macedonian language, published by the Ss. Cyril and Methodius University in Skopje. He has published numerous research papers and has led several research and application projects in the area of Internet technologies and mobile and wireless networks. Also, he has tutored and coordinated many international courses in the ITU Academy. He 
is a Senior Member of IEEE since 2005. His research interests include Internet Technologies, Mobile, Wireless and Multimedia Networks and Services, Traffic Engineering, Quality of Service, Design and Modeling of Telecommunication Networks, as well as Next Generation Networks and Future Networks. 